\title{
Diagnostic endoscopic submucosal dissection with targeted tunnel to reach the suspect area first in order to diagnose muscular invasion and differentiate T1b from $T 2$ cancers
}

Characterization of colorectal neoplasia with Kudo's [1] and Sano's patterns [2] distinguishes superficial neoplasia (submucosal invasion $<1000 \mu \mathrm{m}$ ) displaying Kudo Vi and/or Sano 3a patterns from deep invasive cancers (DIC) $(>1000 \mu \mathrm{m})$ that display Kudo Vn or Sano 3b patterns. Endoscopic submucosal dissection (ESD) is a curative treatment for T1 colorectal cancer with submucosal invasion when the tumor does not display budding, lymphovascular invasion and poorly differentiated components, but depth of invasion over $1000 \mu \mathrm{m}$ is not an independent risk factor of lymph node metastasis [3]. This leads to a new challenge to distinguish lesions with deep submucosal invasion, which are potentially treatable with ESD, from $T 2$ cancers, for which ESD is unfeasible and dangerous since the submucosa disappears below the lesion. Waiting for optical criteria, Japanese experts have proposed attempting ESD with diagnostic intent [4] to obtain, if successful, a precise pathology evaluation (risk factors) to guide further management.

Herein, we present images of a $4-\mathrm{cm}$ nongranular laterally spreading tumor in the left colon in a 63-year-old woman, displaying a $10-\mathrm{mm}$ area with disrupted vessels (Sano 3b) and amorphous pit pattern (Kudo $\mathrm{Vn}$ ) at the center of the lesion (> Fig.1). We attempted diagnostic ESD with targeted submucosal tunneling to explore first the area suspected of deep invasion ( $\downarrow$ Video 1 ). Once we reached it, we were able to confirm tumor invasion through the submucosal space as far as the muscularis propria. Examinations inside and outside the tunnel confirmed the correspondence of the areas ( Fig.2). Biopsy samples from the tunnel confirmed adenocarcinoma in the area of invasion. ESD was stopped without risking perforation and further surgery revealed $\mathrm{T} 2$ adenocarcinoma.

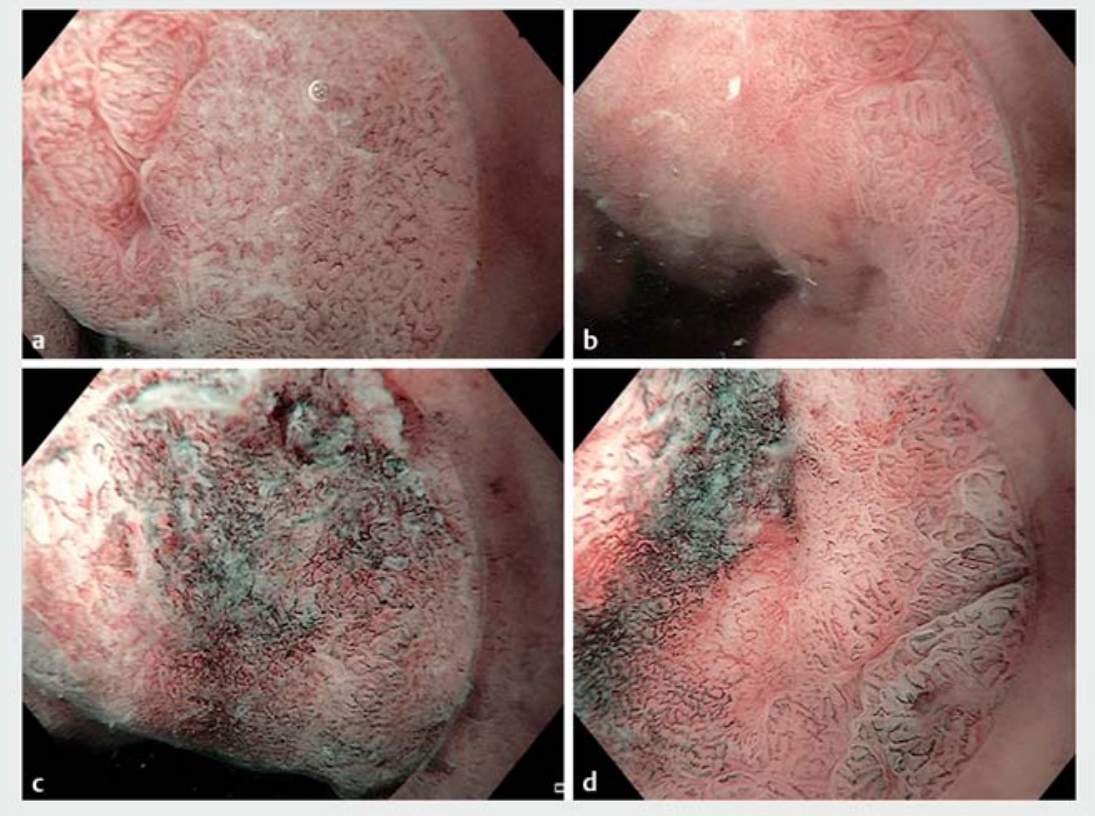

- Fig. 1 Endoscopic optical characterization of a nongranular laterally spreading tumor (LST NG) in a 63-year-old woman. a, b LST NG with noninvasive patterns (Kudo Vi, Sano 3a). c, $\mathbf{d}$ Area of invasive patterns with Kudo $\mathrm{Vn}$ and Sano $3 \mathrm{~b}$ appearance.
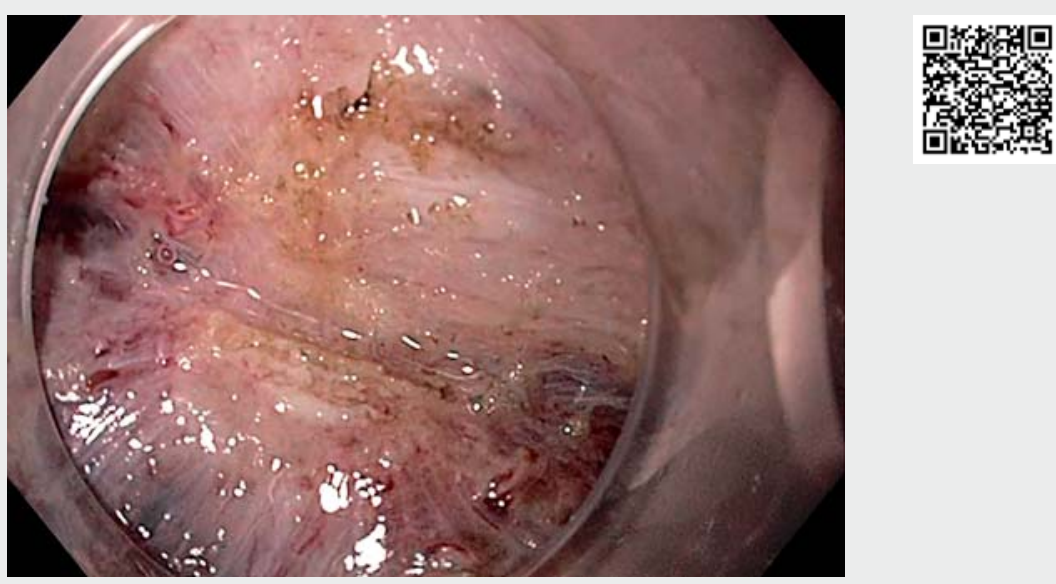

$\checkmark$ Video 1 Diagnostic endoscopic submucosal dissection with a tunnel targeted to the suspect area in order to rule out muscular invasion. 

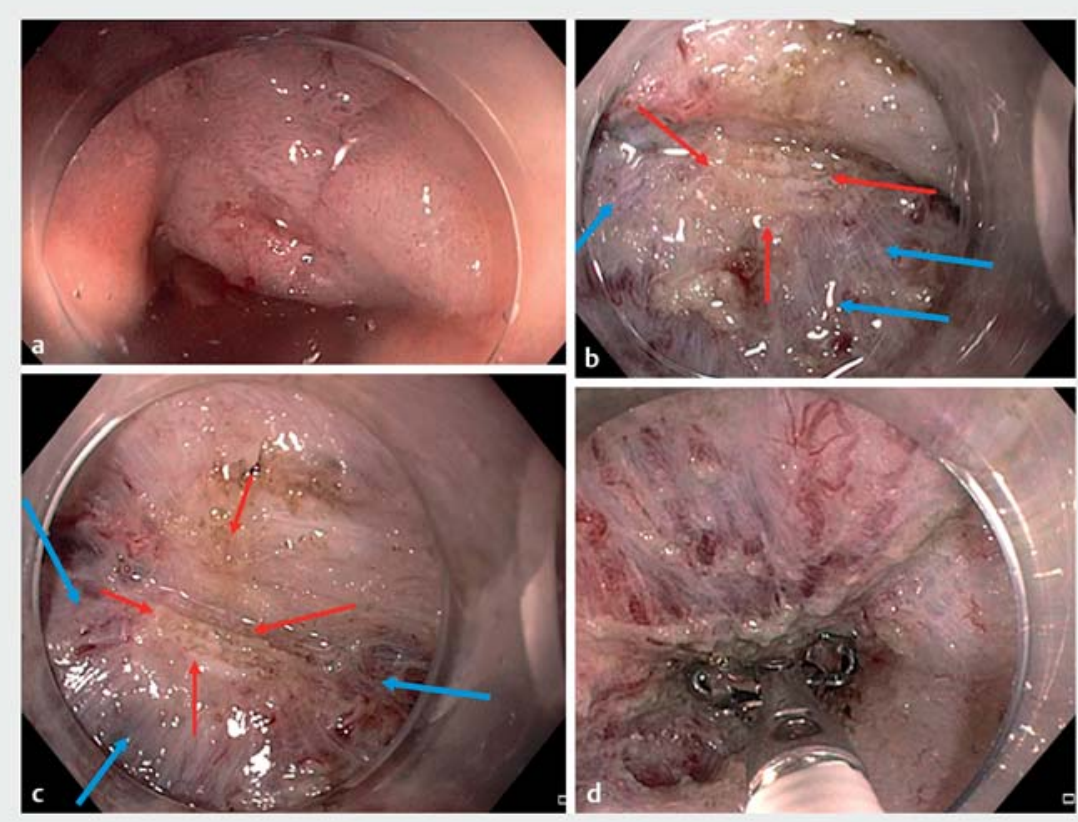

- Fig. 2 Correspondence between the appearances at the surface and in the submucosal tunneling space in the suspect area. a Bluish appearance of the dissected tunnel zone showing local ischemia related to dissection of the underlying submucosa. b, $\mathbf{c}$ In the tunnel, appearance of the focal area of invasion (red arrows) surrounded by injected submucosa (blue arrows). d Biopsy sample revealing adenocarcinoma in the area of invasion.

During the wait for new characterization criteria, diagnostic ESD with a targeted tunnel to reach the suspect area first could allow clinicians to differentiate T1b lesions from T2 ones, stop the ESD, and refer the patient for surgery.

Endoscopy_UCTN_Code_TTT_1AQ_2AD

\section{Competing interests}

The authors declare that they have no conflict of interest.

Camille Meunier ${ }^{1}$, Jérémie Jacques ${ }^{2}$, Jérôme Rivory ${ }^{1}$, Thomas Lambin ${ }^{1}$, Thomas Walter ${ }^{1}$, Thierry Ponchon ${ }^{1}$, Mathieu Pioche ${ }^{1}$

1 Endoscopy and Gastroenterology Unit, Edouard Herriot Hospital, Hospices Civils de Lyon, Lyon, France

2 Gastroenterology and Endoscopy Unit, Dupuytren University Hospital, Limoges, France

\section{Corresponding author}

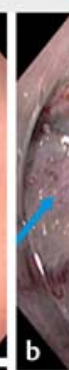

\section{References}

[1] Kudo S, Rubio CA, Teixeira CR et al. Pit pattern in colorectal neoplasia: endoscopic magnifying view. Endoscopy 2001; 33: 367373

[2] Uraoka T, Saito Y, Ikematsu H et al. Sano's capillary pattern classification for narrowband imaging of early colorectal lesions. Dig Endosc 2011; 23 (Suppl. 01): 112-115

[3] Rönnow C-F, Arthursson V, Toth E et al. Lymphovascular infiltration, not depth of invasion, is the critical risk factor of metastases in early colorectal cancer: retrospective population-based cohort study on prospectively collected data, including validation. Ann Surg 2020. doi:10.1097/ SLA.0000000000003854

[4] Saito Y, Uraoka T, Yamaguchi Y et al. A prospective, multicenter study of 1111 colorectal endoscopic submucosal dissections (with video). Gastrointest Endosc 2010; 72: 1217-1225

\section{Bibliography}

Endoscopy 2021; 53: 870-871

DOI 10.1055/a-1268-7057

ISSN 0013-726X

published online 8.10.2021

(c) 2021. Thieme. All rights reserved.

Georg Thieme Verlag KG, Rüdigerstraße 14, 70469 Stuttgart, Germany

\section{Mathieu Pioche, MD}

Endoscopy Unit, Department of Digestive Diseases, Pavillon L - Edouard Herriot Hospital, 69437 Lyon Cedex, France mathieu.pioche@chu-lyon.fr

\section{ENDOSCOPY E-VIDEOS}

https://eref.thieme.de/e-videos

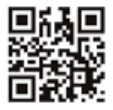

Endoscopy E-Videos is a free access online section, reporting on interesting cases and new techniques in gastroenterological endoscopy. All papers include a high quality video and all contributions are freely accessible online.

This section has its own submission website at

https://mc.manuscriptcentral.com/e-videos 